\title{
Loss of CITED1, an MITF regulator, drives a phenotype switch in vitro and can predict clinical outcome in primary melanoma tumours
}

Jill Howlin, Helena Cirenajwis, Barbara. Lettiero, Johan Staaf, Martin Lauss, Lao Saal, Åke Borg, Sofia K Gruvberger-Saal, Göran B Jönsson

CITED1 is a non-DNA binding transcriptional co-regulator whose expression can distinguish the 'proliferative' from 'invasive' signature in the phenotype-switching model of melanoma. We have found that, in addition to other 'proliferative' signature genes, CITED1 expression is repressed by TGF $\beta$ while the 'invasive' signature genes are upregulated. In agreement, CITED1 positively correlates with MITF expression and can discriminate the MITF-high/pigmentation tumor molecular subtype in a large cohort (120) of melanoma cell lines. Interestingly, CITED1 overexpression significantly suppressed MITF promoter activation, mRNA and protein expression levels while MITF was transiently upregulated following siRNA mediated CITED1 silencing. Conversely, MITF siRNA silencing resulted in CITED1 downregulation indicating a reciprocal relationship. Whole genome expression analysis identified a phenotype shift induced by CITED1 silencing and driven mainly by expression of MITF and a cohort of MITF target genes that were significantly altered. Concomitantly, we found changes in the cell-cycle profile that manifest as transient G1 accumulation, increased expression of CDKN1A and a reduction in cell viability. Additionally, we could predict survival outcome by classifying primary melanoma tumors using our in vitro derived 'CITED1-silenced' gene expression signature. We hypothesize that CITED1 acts a regulator of MITF, functioning to maintain MITF levels in a range compatible with tumourigenesis. 
1 jillian Howlin $^{* 1,2}$, Helena Cirenajwis ${ }^{1}$, Barbara Lettiero ${ }^{1}$, Johan Staaf ${ }^{1}$, Martin

2 Lauss $^{1}$, Lao Saal ${ }^{1}$, Åke Borg ${ }^{1}$, Sofia Gruvberger-Saal ${ }^{1 \S}$ and Göran Jönsson ${ }^{1 \S}$

3 1. Division of Oncology-Pathology, Lund University Cancer Center/Medicon Village,

4 Building 404:B2, Scheelevägen 2, SE-223 81 Lund, Sweden

5 2. Cell and Experimental Pathology, Department of Laboratory Medicine Malmö, Lund

6 University, Sweden.

7 § Equal contribution

\section{$8{ }^{*}$ Corresponding author:}

9 ذillian Howlin, PhD

10 Division of Oncology-Pathology, Lund University Cancer Center/Medicon Village,

11 Building 404:B2, Scheelevägen 2, SE-223 81 Lund, Sweden

12 Tel: $+46(0) 709106498$

13 Email: jillian.howlin@med.lu.se 


\section{INTRODUCTION}

15 CITED1 is the founding member of the CITED (CBP/p300-interacting

16 transactivator with glutamic acid [E]/aspartic acid [D]-rich C-terminal

17 domain) family of transcriptional co-regulators and was originally cloned from

18 a differential display screen between pigmented mouse B16 melanoma cells

19 and their dedifferentiated weakly-pigmented derivative, B16F10s. This led to

20 speculation that CITED1 or msg1 (melanocyte specific gene 1 ) as it was

21 known at that time, was involved in the process of pigmentation (Shioda,

22 Fenner and Isselbacher, 1996). Subsequently, Nair et al. reported that stable

23 overexpression of CITED1 increased the levels of tyrosinase, dopachrome

24 tautomerase (Dct) and melanin in B16 cells, reinforcing the idea that it had a

25 role in melanogenesis (Nair et al., 2001). By 2005, as gene expression

26 profiling became relatively commonplace, CITED1 was identified in several

27 new screens of tumours and cell lines: two studies identified CITED1 as a

28 gene whose expression distinguished nevi from primary melanoma, another

29 found CITED1 to be upregulated in advanced stage melanomas in comparison

30 to benign nevi or melanoma in situ, while expression profiling of an in vitro

31 progression model identified CITED1 among a signature of genes lost in

32 aggressive melanoma lines relative to primary melanocytes in culture (Ryu et

33 al., 2007; Haqq et al., 2005; Talantov, 2005; Smith, Hoek and Becker, 2005).

34 Based on extensive gene expression profiling of melanoma cell lines in vitro,

35 Hoek et al. proposed the 'phenotype-switching' model of melanoma that was

36 independent of the degree of transformation or disease progression, and 


\section{PeerJ Reviewing Manuscript}

37 sought to explain the observation that melanoma cells altered between two

38 states: those with high proliferative potential that are less invasive and those

39 with high metastatic potential that are less proliferative. These separate but

40 alternating states are controlled by different transcriptional programs and

41 can be defined by specific gene signatures (Hoek, Eichhoff, et al., 2008). MITF

42 expression and many of its known targets (TYR, MLANA) define the

43 'proliferative' group, while the 'invasive' signature group is characterized by

44 expression of negative regulators of the Wnt signalling pathway (WNT5A,

45 DKK1, CTGF). CITED1 expression was associated with the proliferative

46 pathway signature and subsequently confirmed in an updated and expanded

47 data set to be significantly correlated with the proliferative phenotype

48 (P<1.00E-05, http://www.jurmo.ch/hopp, accessed 19 March 2013) (Hoek et

49 al., 2006); (Widmer et al., 2012).

50 Studies on CITED1 suggest that it is a non-DNA binding nuclear

51 transcriptional co-regulator capable of influencing TGF $\beta$ induced transcription

52 mediated by ligand-induced SMAD hetero-oligomerization; estrogen-

53 dependent transcription mediated by $E R \alpha$, and Wnt/ $\beta$-Catenin-dependent

54 transcription. These effects are dependent on CITED1-CBP/P300 binding via

55 the conserved CITED family CR2 domain and while CITED1 is thought to act

56 by stabilizing the CBP/P300-ER $\alpha$ interaction, in the case of $\beta$-Catenin it acts to

57 repress transcription by competing for binding with CBP/P300 transcriptional

58 co-activators (Shioda et al., 1998; Yahata et al., 2001; 2000; Plisov, 2005). 
59 Microphthalmia-associated transcription factor, MITF, acts as a master-

60 regulator of melanocyte differentiation and as a result has been intensely

61 studied in the field of melanoma research (Widlund and Fisher, 2003; Levy,

62 Khaled and Fisher, 2006). It is a basic helix-loop-helix leucine zipper

63 transcription factor that recognizes E-box and M-box sequences in the

64 promoter regions of its target genes. Highlighting its importance in the

65 disease, amplification of MITF locus has been found in $>15 \%$ of metastatic

66 melanomas and germline mutations in MITF that predispose carriers to

67 melanoma development have also been found (Garraway et al., 2005;

68 Bertolotto et al., 2011; Yokoyama et al., 2011). In melanoma cells the target

69 genes of MITF include most notably TYR, MCIR, DCT, MLANA involved in the

70 process of pigmentation; cell cycle regulators such as CDK2 and CDKN1A and

71 the more recently identified BRCA1 gene that has, with other target DNA

72 repair genes, defined a role for MITF in the DNA damage response (DDR)

73 (Strub et al., 2011; Beuret et al., 2011; Giuliano et al., 2010).

74 The regulation of MITF is complex and tightly controlled, exhibiting both

75 transcriptional and post-translational regulation. There are several transcript

76 isoforms, of which MITF-M is the dominant form expressed in melanocytes.

77 Multiple signalling pathways converge on the MITF-M specific promoter that

78 harbours binding sites for PAX3, SOX10, CREB, FOXD3, LEF-1 and BRN2

79 among other transcription factors (Yokoyama and Fisher, 2011; Levy, Khaled

80 and Fisher, 2006). Additionally, the MITF target gene CDKN1A/P21 has been

81 shown to act as reciprocal transcriptional cofactor independently of its CDK 
82 inhibitor function, suggesting the existence of at least one positive feedback

83 loop (Sestáková, Ondrusová and Vachtenheim, 2010).

84 MITF post-translational activity can be affected by phosphorylation,

85 sumoylation, ubiquitination and by binding with proteins that block access to 86 the DNA binding domain such as PIAS3 (Yokoyama and Fisher, 2011; Levy,

87 2001). Oncogenic BRAF (but not wildtype BRAF), which is mutated in up to $8850 \%$ of melanomas, also regulates MITF via simultaneously stimulating MITF 89 activation through ERK phosphorylation, which leads to its subsequent 90 degradation, and by inducing transcription of MITF via BRN2 upregulation 91 (Davies et al., 2002; Wellbrock et al., 2008).

92 The consensus regarding why the cell invests such effort in maintaining 93 control of MITF levels and why there are so many regulatory mechanisms, is 94 that melanocytes and melanoma are exquisitely sensitive to even small 95 variations in MITF expression. Ultimately its activity must be sustained within 96 the narrow window permissive for continued survival and proliferation. In this 97 study, we characterise the role of CITED1 as a novel regulator of MITF in 98 melanoma. 
102 McCoy's5A supplemented with $10 \%$ and 15\% foetal bovine serum (FBS),

103 respectively. A2058, WM852 and WM239 were cultured in RPMI 1640

104 supplemented with 10\% FBS; A375 and HMBC cells were cultured in DMEM

105 supplemented with 10\% FBS and SKMEL5 cells were cultured in MEM media

106 supplemented with 10\% FBS. Cells were grown in the presence of penicillin

107 and streptomycin (50 I.U./mL) purchased from Invitrogen. Cell media and FBS

108 were purchased from ThermosScientific, HyClone range. As of March 2014,

109 these are part of the Life Technologies (Thermo Fisher Scientific) product 110 portfolio.

\section{Gene expression analysis}

112 RNA was isolated (4 replicates for each treatment) using a Qiagen RNeasy

113 Plus mini-kit and the quality determined using a Bioanalyser (Agilent).

114 Replicates were cell samples from separate wells, but plated on the same day

115 and derived from the same passage number. Gene expression experiments

116 were performed using the Illumina HT12 array covering more than 47,000

117 transcripts and known splice variants across the human transcriptome. The

118 raw data was quantile normalized and Illumina control probes were removed

119 from subsequent analysis using BASE (Vallon-Christersson et al., 2009). The

120 data were exported to $\mathrm{MeV}$, log2 transformed and gene and sample centred

121 (Saeed et al., 2006). SAM (significance of microarray analysis) was performed

122 using a two-group comparison; for the siRNA experiment the groups

123 corresponded to siNEG vs. \#1 \& \#3 siCITED1 and for the TGF $\beta 1$ experiment

124 the groups corresponded to cells with or without TGF $\beta 1$ treatment. In both 
125 cases there was a median false discovery risk of 10 false-positive transcripts.

126 Hierarchical clustering was performed to visualize the data. 1009 probes

127 were significantly altered by TGF $\beta 1$ treatment while 312 probes were found to

128 be significantly altered in the siRNA experiment (208 upregulated and 104

129 downregulated). These data can be found in Supplemental files S7 and S8,

130 respectively. DAVID was used to assist in functional annotation of the final

131 gene lists (Huang et al., 2007)

132 For the publically available data cited, 120 melanoma cell lines from three

133 cohorts ((Johansson, Pavey and Hayward, 2007); (Hoek et al., 2006);

134 (Greshock et al., 2010)) analysed by Affymetrix gene expression microarrays

135 were collected, individually MAS5 normalized, and merged into a single

136 cohort. Probe sets were collapsed into single genes and mean-centred across

137 the entire cohort. These 120 cell lines and their associated normalized

138 expression data can be found in supplemental data S10. Data from Harbst et

139 al. were classified using nearest centroid and Pearson correlation. Survival

140 analysis and multivariate cox regression methods were performed in $\mathrm{R}$.

141 Transient transfections, promoter-reporter assay and TGF $\beta 1$ -

142 treatment

Transient transfections were performed using

143 Lipofectamine2000 and Opti-MEM reduced serum media (Life Technologies)

144 according to the manufactures recommendations. siRNA was purchased from

145 Applied Biosystems and the notations in the text: siNEG, \#1 siCITED1 and \#3

146 siCITED1 correspond to the catalogue ID numbers \#4390843, \#s8965 and 


\section{PeerJ Reviewing Manuscript}

147 \#s224062 respectively. For the MITF targeting siRNA; N, siM1 and siM3

148 correspond to the catalogue ID numbers \#4390843, \#s8790 and \#ss8792,

149 respectively. For the luciferase reporter assay, a Dual-Luciferase Reporter

150 assay system \#E1910 (Promega) was used to measure relative reporter

151 activity on a FLUOstar Omeaga microplate reader (BMG Labtech). A375 cells

152 were transfected with a luciferase reporter construct harbouring $2.3 \mathrm{~kb}$ of the

153 MITF-M specific promoter in a PGL2 vector (Wellbrock et al., 2008). A pRL-

154 Renilla Luciferase reporter vector was used as a control for each transfection.

155 CITED1 was overexpressed using a pRc/CMV containing a N-terminal HA-

156 tagged human CITED1 (transcript isoform 1) referred to as pCITED1 in the

157 text (Shioda, Fenner and Isselbacher, 1996). An empty CMV-promoter

158 expression plasmid, pcDNA3.1 (+) was used a negative control. Recombinant

159 human transforming growth factor- $\beta 1$ (TGF $\beta 1$ ), \#PHG9203 was purchased

160 from Invitrogen. For the A2058 gene expression experiment, cells were

161 exposed to either 5 or $10 \mathrm{ng} / \mathrm{ml} \mathrm{TGF} \beta 1$ in serum-free media for 24 hours. In

162 the case of the Luciferase reporter assay, cells were serum starved the day

163 after transfection for 3 hours and exposed to $5 \mathrm{ng} / \mathrm{ml}$ TGF $\beta 1$ in serum free 164 media for 24 hours prior to harvesting.

\section{Antibodies and Immunoblotting}

166 The following antibodies were used: anti-CITED1, \#AB15096 from Abcam;

167 anti-MITF (C5 clone), \# MA5-14146 from ThermoScientific; anti-MITF (D5 168 clone) from Dako, \#M3621, (used in Fig. 4c); anti-CDKN1A/P21, \#2947 and 
169 anti-CDKN1C/P57, \#2557 were purchased from CellSignaling Technology and

170 anti- $\beta$-Actin (AC-15), \#A5441 from Sigma-Aldrich. Cell lysates were resolved

171 by SDS-PAGE (pre-cast gels purchased from Life Technologies) and

172 transferred to $0.45 \mu \mathrm{m}$ PVDF membranes purchased from Millipore by

173 electroblotting. The membranes were blocked in 5\% non-fat milk in TBST

174 prior to incubation with primary antibodies diluted $2.5 \%$ non-fat milk. The

175 blots were probed with the appropriate secondary antibodies (Pierce

176 Biotechnology) in 5\% non-fat milk. The membranes were developed using

177 ECL (GE Healthcare). A note on reproducibility: Western blots were performed

178 for a variety of purposes; in cases where it was simply a control to establish if

179 siRNA downregulation had been successful, or confirm that an observation

180 seen on mRNA level was also reflective of protein level, then there may have

181 been only one Western blot performed on those particular samples (although

182 often technical repeats were performed). In contrast, observations that were

183 key to the hypothesis presented were performed a number of times to ensure

184 reproducibility e.g.: The effect of siCITED1 on upregulation of MITF and

185 CITED1 overexpression on MITF downregulation was seen on samples for

186 multiple experiments performed (i.e.: >3): protein samples were used to

187 confirm the initial observations from the GEX (using two siRNAs at two

188 different timepoints) and two transfection of different amounts of pCITED1

189 plasmid; subsequently, two sets of timecourse experiments were performed

190 to establish the effect independently, at both mRNA and protein level. The

191 effect on P57 was initially observed using transfection of two different

192 amounts pCITED1 plasmid and subsequently confirmed at multiple timepoints 
193 in both of two separate sets of timecourse experiments. The P21 effect was

194 observed at single timepoint following siCITED1 treatment in both of two

195 separate timecourse experiments. For the reciprocal effect of siMITF on

196 CITED1 it should be noted that the effect was observed in 3 different cells

197 lines, using at least two separate transfections.

\section{Cell cycle analysis}

199 Flow cytometry was performed on a FACSCalibur (BD Biosciences) and 200 subsequently analysed using ModFit (Verity House Software). Briefly,

201 following transfection, confluent cells were detached, washed in 1XPBS and 202 fixed in $70 \%$ ethanol. Prior to analysis they were stained with a propidium

203 iodide solution and a $20 \mathrm{G}$ syringe was used to obtain a homogenous single 204 cell solution. All events were saved (up to 20,000 events per replicate) 205 ungated, using BD Cell Quest and the data exported to ModFit where 206 following selection of the appropriate ploidy status, a standard auto-analysis 207 fit using autolinerarity was performed. We found that a 2-cycle aneuploid208 dip/tetraploid was appropriate for HT144 and A2058 while 1-cycle diploid was 209 suitable for $\mathrm{A} 375$.

\section{Alamar Blue Assay}

211 The Alamar blue assay reagent was purchased from Invitrogen (Life

212 Technologies) and used according to the manufactures' instructions. Briefly, 213 following transfection cells were seeded into 96 -well plates at 5000cells/well.

214 In each experiment, for each of the treatments i.e.: siNEG, \#1 siCITED1 and 


\section{PeerJ Reviewing Manuscript}

215 \#3 siCITED1, 8 wells spread over 3 rows were used. At the indicated time

216 points $(4,72,96$ and 120 hours post-transfection), Alamar blue was added

217 and the cells incubated at $37^{\circ} \mathrm{C}$ for 2 hours. Fluorescence was measured

$218(544 \mathrm{~nm})$ on a FLUOstar Omeaga microplate reader (BMG Labtech). The

219 values obtained at the 4-hour time point were used to normalize the

220 fluorescence readings to account for any initial cell counting error. Cells were

221 also seeded in parallel for Western blot analysis (72, 96, 120 hours) to ensure

222 successful CITED1 down regulation.

\section{Droplet digital PCR}

224 RNA was isolated from cells using a Qiagen RNeasy Plus mini-kit and

225 quantified using a Nanodrop spectrophotometer (ThermoScientific). cDNA

226 was generated from 50-100ng total RNAs using 'iScript Advanced cDNA

227 synthesis for RT-qPCR' (Bio-Rad). Bio-RAD's 'ddPCR Supermix for Probes' was

228 then used with predesigned TaqMan gene expression assays (Applied

229 Biosystems) consisting of specific primers and FAM labelled probes for MITF

230 (\#Hs01117294_m1), MITF-M isoform specific transcript (Hs00165165_m1)*,

231 CITED1 (\#Hs00918445_g1) and IPO8 (\#Hs00183533_m1). (*There appeared

232 to be no advantage in using the MITF-M isoform specific transcript over the 233 MITF probe that could measure multiple isoforms). A manual cut-off for

234 positive/negative droplets was selected using the Bio-Rad QuantaSoft ${ }^{\mathrm{TM}}$ data 235 analysis suite to calculate the relative copies/ $\mu$ l of each transcript. 
236 RESULTS

237 TGF $\beta$ induces expression of the invasive signature genes while

238 suppressing a cohort of proliferative signature genes including

\section{CITED1}

240 Hoek et al. noted that many of the genes that defined the invasive

241 phenotype were commonly TGF $\beta$-driven while at the same time only the

242 proliferative signature phenotype cells were sensitive to TGF $\beta$ growth

243 inhibition in vitro (Hoek et al., 2006). That MITF levels decrease and

244 invasiveness is enhanced in response to TGF $\beta$ stimulation was also confirmed

245 subsequently (Pierrat et al., 2012; Pinner et al., 2009). In agreement, we

246 showed that the melanoma cell line A2058 upregulates WNT5A in response to

247 TGF $\beta$ exposure and that exogenous Wnt-5a in turn, increased their invasive

248 potential (Jenei et al., 2009). For the present study, in an effort to examine

249 what other phenotype specifying genes were directly regulated by TGF $\beta$, we

250 performed gene expression analysis and found TGF $\beta$ treatment resulted in

251 both upregulation of invasive signature genes and suppression of genes

252 characterizing the proliferative phenotype using a SAM two-group

253 comparison (Fig. 1a and Material \& Methods section). The effect is most

254 pronounced if only those signature genes that were deemed significantly

255 altered by TGF $\beta$ treatment are examined. The original signature set defined

256 by Hoek et al., was redefined as more public datasets became available and

257 has a slightly different but overlapping gene profile based on the top ranked

258 differentially expressed genes (Fig. 1b). Both MITF and CITED1 are in the 
259 proliferative cohort and their response to TGF $\beta$ treatment was confirmed at 260 protein level in A2058 cells (Fig. 1C).

261 CITED1 expression positively correlates with the expression of MITF

262 Examination of publically available gene expression data on 120 melanoma

263 cell lines demonstrated a consistent positive correlation between CITED1 and 264 MITF expression $(r=0.6543)$. Each cell line was assigned as either 265 'proliferative' or 'invasive' based on a score derived from the averaged 266 expression values of the approximately 50 genes in each defining signature

267 set that had matching gene symbols in our data (Fig. 2a). We also confirmed 268 the correlation in cell lines derived from our own lab (Fig. S1). This was 269 important as inconsistency in interlaboratory phenotype signatures has 270 previously been reported (Widmer et al., 2012). We could additionally confirm 271 expression at the protein level (Fig. 2b)

272 Gene expression analysis reveals CITED1 silencing can induce a 273 phenotype-switch

274 To investigate the function of CITED1 in melanoma, we transiently

275 downregulated its expression using CITED1 targeting siRNA. We choose the $276 \mathrm{HT} 144$ cell line as it had a relatively high level of detectable CITED1 mRNA 277 and protein expression. A scatterplot of the 120 cell lines assigned as either 278 'proliferative' or 'invasive' based on the maximum matching gene signature 279 score, demonstrates the shift in phenotype that occurs following CITED1 280 downregulation (Fig. 3a,b). A heatmap of the expression profiles clearly 281 illustrates that the shift is due to a general induction of the 'proliferative' and 


\section{PeerJ Reviewing Manuscript}

282 suppression of the 'invasive' cohort (Fig. 3c). It was apparent that the \#3 283 siCITED1 siRNA was not as effective at switching the cells as the \#1

284 siCITED1, this was observed consistently throughout our experiments and 285 may be due to the fact that \#3 siCITED1 was not as successful at silencing 286 CITED1 (Fig. 3b, inset).

287 CITED1 is a reciprocal regulator of MITF and impacts MITF target 288 gene expression

289 A heatmap highlights the identity of only the significantly differentially 290 induced transcripts between siNEG and both \#1 \& \#3 siCITED1 (Fig. 4a). Of 291 most relevance, we found MITF, a known driver of the proliferative phenotype 292 switch and many of its previously known downstream targets, these also 293 included genes categorized by Gene Ontology annotation (GO) as related to 294 pigmentation and UV/DNA damage response (Fig. 4a) (Hoek, Schlegel, et al., 295 2008; McGill et al., 2006; Sánchez-Martín et al., 2002; Strub et al., 2011). We 296 could confirm that indeed MITF protein levels were affected by siCITED1 in 297 HT144 cells and that conversely, overexpression of CITED1 in A2058 cells, 298 resulted in downregulation of MITF (Fig. 4b). Strub et al. identified a large 299 number of genomic targets of MITF by ChIP-seq analysis (Strub et al., 2011). 300 A comparison of the genes differentially expressed by siCITED1 compared to 301 siNEG, revealed that there was significant enrichment of these potential 302 targets (Fig. S2a). Notably, genes both up and down regulated by siCITED1 303 are represented among genes defined as having MITF-occupied promoters 304 (Fig. S2b). We also found that downregulation of MITF using siRNA in HT144 
305 cells (Fig. 4c) and in WM293A, and SKMEL5 cells (Fig. S3a, b) resulted in

306 decreased protein expression of CITED1 suggesting reciprocity between these 307 factors.

308 Induction of MITF by CITED1 silencing transiently restrains cell cycle 309 progression and impacts cell viability

310 To investigate the effect of CITED1 silencing on melanoma cells behaviour we

311 analysed the cell cycle distribution following siRNA treatment, by flow

312 cytometry. In siCITED1 treated HT144 cells we saw G1 accumulation as

313 indicated by an increase in the diploid G1 fraction and a concomitant

314 reduction in the total S-phase fraction peaking at 33 hours but also observed

315 at 48 and 72 hours post-transfection in comparison to siRNA control HT144

316 cells. Again, the effect was apparent but not as pronounced using the \#3

317 siCITED1 (Fig S4a). Similar effects were seen in \#1 and \#3 siCITED1 treated 318 A2058 and A375 cells (Fig. S4b, c).

319 Owing to the previously reported dependency of MITF-induced cell cycle

320 arrest on CDKN1A/P21 we investigated the levels of several cyclin-dependant

321 kinase inhibitors following CITED1 silencing (Carreira et al., 2005). We found

322 that CDKN1A/P21 was transiently increased in siCITED1 treated HT144 cells

323 relative to the siNEG treated HT144 cells (Fig 5b). In contrast, in A2058 cells,

324 which do not have detectable levels of CDKN1A/P21 (Fig. S5), the levels of

325 CDKN1C/P57 were supressed in response to CITED1 overexpression (Fig 5b).

326 We hypothesised therefore that melanoma cells can utilise either 
327 CDKN1A/P21 or CDKN1C/P57 to mediate cell cycle arrest induced by MITF and

328 this is reflected in the expression levels of the alternate CDK inhibitors in

329 different melanoma cell lines (Fig. S5).

330

331 In agreement with the cell cycle data, an Alamar Blue assay revealed a

332 significant reduction in cell viability as measured by metabolic activity over 5

333 days in HT144 cells treated with siCITED1 (Fig 5c). The effect was apparent

334 but not as pronounced in the \#3 siCITED1 sample.

335 The effect of CITED1 silencing on MITF is transient and mediated via 336 promoter activation

337 We observed that the peak upregulation of MITF and CDKN1A/P21 protein 338 following siCITED1 treatment varied from transfection to transfection, being 339 seen between 24-48 hours post-transfection but appearing as unchanged or 340 even downregulated after this time (Fig. 6a, upper panel). In agreement, later 341 timepoints of the cell cycle analysis ( $=/>72$ hours) exhibited little or no 342 change in G1/S-phase distribution or even a reverse pattern (Fig. 5a HT144, 343 and data not shown: A2058, A375). We therefore sought to examine the 344 transcriptional dynamics more closely, map the changes in MITF following 345 CITED1 silencing and see if they corresponded to cell behaviour and changes 346 at the protein level. We used a quantitative droplet digital PCR based assay 347 (Bio-Rad) to measure mRNA in HT144 cells transfected with siCITED1\#1 and 348 siNEG as well as A2058 cells transiently overexpressing CITED1 compared to 349 an empty vector control. MITF, CITED1 and IPO8 specific primers and probes 


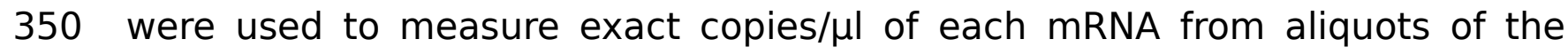

351 same cDNA solution. Plots of siCITED1(copies/ $/$ l)/siNEG(copies/ $\mu \mathrm{l})$ and

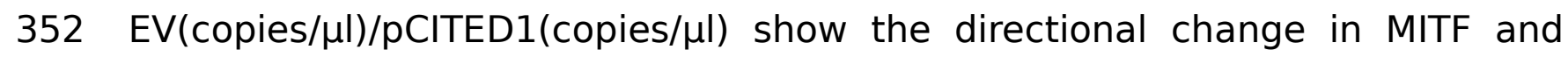

353 CITED1 relative to the housekeeper IPO8. CITED1 expression is rapidly

354 supressed following siCITED1 treatment of HT144 cells, concomitant with an

355 upregulation of MITF that diminishes over time and in fact is supressed by

356100 hours in accordance with observations at the protein level (Fig 6a, lower

357 panel). In contrast, overexpression of CITED1 in A2058 cells results in

358 transient suppression of MITF at both protein and transcript level (Fig. 6b,

359 upper and lower panels).

360 The rapid MITF transcriptional response to CITED1 manipulation suggested to

361 us that the effect could be directly mediated at the promoter level. To test

362 this hypothesis, we over expressed an MITF-M promoter-reporter construct

363 and CITED1 in A375 cells. We chose A375 cells, as while they had less

364 endogenous CITED1 and MITF than HT144 or A2058 so as not to cause 365 interference with the assay, we also knew that they could respond 366 adequately as they had an identical G1 accumulation/S-phase decrease to

367 both HT144 and A2058 cells following CITED1 silencing (Fig S4c). TGF $\beta$ 368 treatment was used as a positive control for repression of the MITF-M 369 promoter. CITED1 transfection led to significant suppression of the MITF-M

370 promoter luciferase activity relative to the empty vector control, as did TGF $\beta$

371 treatment alone or combination with CITED1 overexpression (Fig. 6c). There

372 did not appear to be an additive or synergistic effect using both TGF $\beta$ 
373 treatment and CITED1 overexpression suggesting TGF $\beta$ may be dependent on

374 CITED1 for MITF suppression.

375 The CITED1-silenced gene signature predicts outcome in primary

\section{6 melanoma}

377 The 'proliferative' and 'invasive' signature phenotypes have served to define

378 the gene expression classification of melanoma cell lines. However, primary

379 tumours and metastatic lesions have also been molecularly classified into

380 several distinct groups by gene expression profiling (Harbst et al., 2012;

381 Jonsson et al., 2010). The four-class structure found in tumours consists of

382 the 'pigmentation', 'proliferative', 'high-immune' and 'normal-like' subgroups

383 with a subset falling into an unclassifiable cohort (Jonsson et al., 2010). We

384 used the same tumour classification to subtype the 120 cell lines that had

385 publically available expression data and could show that the tumour

386 'pigmentation' subgroup that highly expresses MITF, corresponds to the cell

387 line 'proliferative' phenotype described by Hoek et al. Accordingly, the

388 tumour 'proliferative' and 'high-immune' subgroups comprise the cell line

389 'invasive' phenotype (Fig. 7a). It is worth noting that the names of the tumour

390 subgroups were derived from a description of the differentially expressed

391 genes that comprised each molecular classification while the 'invasive-

392 proliferative' switching phenotypes were named to reflect the behaviour

393 exhibited by lines classified by one or other signature. This distinction helps

394 to explain the confusing occurrence that both classifications have a group

395 referred to as 'proliferative' although they are not equivalent. 
396 The overlap between the primary tumour classifying and cell line classifying

397 systems allows us to infer that CITED1 expression is most likely restricted to

398 a subset of MITF high 'pigmentation' subtype tumours. As the tumour

399 subtype classification was shown to be prognostically significant in primary

400 melanomas we were interested to know if CITED1 expression itself was

401 independently predictive of outcome. Previously we reported on the analysis

402 of 223 primary lesions using the Illumina WG-DASL protocol (Harbst et al.,

403 2012). As the CITED1 probe in this assay did not produce reliable data we

404 instead derived a CITED1-silenced gene signature score based on the 405 differentially expressed genes from the HT144 siCITED1 experiment (Fig. 3).

406 We therefore effectively created a multi-gene surrogate expression signature 407 rather than using CITED1 gene expression itself. We subsequently 408 interrogated the gene expression data on the primary melanoma lesions 409 using a nearest centroid approach derived from the CITED1-silenced gene 410 signature. This revealed that primary melanomas with a gene expression 411 signature most similar to the CITED1-silenced signature (CITED1low-class)

412 had a significantly better outcome than those with a signature most disparate 413 from the CITED1-silenced signature (CITED1high-class) (Fig. 7b). Importantly, 414 the CITED1 signature classing had independent prognostic information (HR $4151.85, \mathrm{Cl} 0.30-0.98, \mathrm{p}=0.044)$ from the AJCC staging system (HR 5.05, Cl 2.42416 10.55, $p=1.64 \times 10-5)$. Accepting the caveat that we depend here on a proxy 417 gene-signature, these data indirectly imply that CITED1 expression is a 418 potential prognostic indicator in primary melanomas and the transcriptional 


\section{PeerJ Reviewing Manuscript}

419 program influenced by CITED1 expression determines tumour behaviour in 420 vivo.

\section{DISCUSSION}

422 One seemingly paradoxical observation from our study and previous

423 investigations is that although CITED1 behaves as a negative regulator of

424 MITF, both their expression levels appear positively correlated across cells

425 lines and tumours. We maintain that this observation simply reflects the fact

426 that where there are high levels of MITF, high levels of its negative regulator

427 are also required. The evidence of the tight control exerted over MITF levels

428 in melanocytes and melanoma simply speaks to the necessity of the cell to

429 maintain a level compatible with survival and proliferation, in a type of

430 biological 'sweet-spot' facilitating tumour progression. The cellular effects of

431 both extremes i.e.: very low or high levels of MITF, have been elegantly 432 described by a rheostat model in order to reconcile the conflicting

433 observations of the effects of manipulating MITF in vitro, and the fact that 434 counter-intuitively, a lineage-specifying differentiation factor can behave as a 435 potent oncogene (Hoek and Goding, 2010; Carreira et al., 2006; Cheli, 436 Giuliano, et al., 2011). The rheostat model (Fig. S6) attempts to explain why 437 MITF silencing can block cells in G1 and induce senescence, while it is also 438 possible to induce a G1 arrest by MITF overexpression via CDKN2A/P16 or 439 CDKN1A/P21 and, as we now propose, potentially also via CDKN1C/P57 440 (Carreira et al., 2006; Loercher et al., 2005; Carreira et al., 2005). At the 441 extreme high end of MITF expression lies differentiated melanocytic cells, 


\section{PeerJ Reviewing Manuscript}

442 while the lowest levels can lead to senescence and irreversible cell death.

443 Between these two extremes however it is thought that melanoma cells can 444 oscillate from a low-MITF 'invasive' to a high-MITF 'proliferative' state via 445 phenotype-switching.

446 We hypothesise that the role of CITED1 in melanoma is to maintain levels of

447 MITF compatible with tumour progression and effectively tip the balance in

448 favour of cell cycle progression rather than MITF-induced G1-arrest. This is 449 supported by our findings that downregulation of CITED1 using siRNA results 450 in a phenotype switch to a more pigmented state driven by increased MITF 451 expression and concomitant upregulation of CDKN1A/P21. Conversely, we 452 could observe that downregulation of MITF resulted in suppression of CITED1 453 in several cell lines suggesting the existence of a classical feedback loop 454 where low MITF levels result in inhibition of its negative regulator. MITF 455 induced cell cycle arrest was previously shown to be dependent on 456 CDKN1A/P21 and it was demonstrated that MITF does not cause a cell cycle 457 arrest in CDKN1A-deficient mouse embryo fibroblasts (MEF) cells (Carreira et 458 al., 2005). However, our data indicate that in melanoma cells deficient in 459 CDKN1A/P21, the alternative CDK inhibitor CDKN1C/P57 is expressed and 460 responsive to MITF.

461 Interestingly, while we observed upregulation of most MITF targets following 462 CITED1 silencing, we found that BRCA1 and other DNA damage response 463 (DDR) genes were supressed, suggesting that CITED1 downregulation does 


\section{PeerJ Reviewing Manuscript}

464 not necessarily facilitate transcription of all MITF targets. It is thus tempting

465 to speculate that rather than simply acting to induce MITF and thereby

466 indirectly enhance transcription of its target genes, that CITED1 may also act

467 as co-factor for MITF at various genomic locations differentially modulating

468 the MITF target gene response at individual promoters. One way that this

469 might be achieved is via MITF-CITED1 competition for CBP/P300 binding as

$470 \mathrm{CBP} / \mathrm{P300}$ is a known transcriptional coregulator for MITF, although it is not

471 required for transcription of all MITF targets (Vachtenheim, Šestáková and

472 Tuháčková, 2007; Yan et al., 2013).

473 As suggested by Sáez-Ayala et al., anti-cancer therapy should be ideally

474 independent of dominant or 'driver' genetic alterations so that subclonal

475 populations do not gain a subsequent advantage and the same holds true in

476 the case of targeting a specific phenotype. Successful therapy will

477 necessarily need to switch or push the subdominant phenotype into the

478 susceptible state or eradicate the phenotype resistant to treatment. This

479 approach was initially championed by Cheli et al., who proposed the 480 eradication of low-MITF cells as a therapeutic strategy (Cheli, Guiliano, et al.,

481 2011). Indeed the idea of lineage-specific therapy has been subsequently 482 proved in principle using methotrexate (MTX) to first activate MITF 483 expression, in turn activating the tyrosinase enzyme, and thereby sensitising 484 tumour cells to a tyrosinase-processed anti-folate prodrug (TMECG) (Sáez485 Ayala et al., 2013). However, even without drug targeting, induction of MITF, 486 to levels seen in melanocytes or above what is tolerated by even the highly 


\section{PeerJ Reviewing Manuscript}

487 pigmented tumour cell types, would seem to be incompatible with melanoma

488 progression as it can inhibit cell cycle progression (Goding, 2013). Our

489 assertion is that CITED1 acts to repress MITF in order to maintain its level in a

490 range compatible with tumorigenesis. This assertion as a consequence

491 naturally suggests CITED1 as therapeutic target for genetic manipulation.

492 Successful implementation of such a strategy would result in cell specific

493 enhancement of MITF expression and increased susceptibility to the type of

494 chemotherapeutic eradication demonstrated by Sáez-Ayala et al. or

495 potentially induction of CDKN1A/p21 or CDKN1C/p57-dependent cell growth

496 arrest even without further intervention (Fig. S6) (Sáez-Ayala et al., 2013).

\section{Acknowledgements}

498 We would like to thank Dr. Claudia Wellbrock (University of Manchester, UK)

499 for the kind gift of the PG2-MITF promoter-reporter construct and Prof. Toshi

500 Shioda (MGH, Harvard) for the human CITED1 pRc/CMV expression vector. We

501 also would like to acknowledge Prof. Bo Baldetorp (Division of Oncology, Lund

502 University) for his advice on cell cycle analysis and the support of Prof.

503 Tommy Andersson (Cell and Experimental Pathology, ILMM, Lund University).

\section{References}

505 Bertolotto, C., Lesueur, F., Giuliano, S., Strub, T., de Lichy, M., Bille, K., Dessen, P., d'Hayer, B., 506 Mohamdi, H., Remenieras, A., Maubec, E., la Fouchardière, de, A., Molinié, V., Vabres, P.,

507 Dalle, S., Poulalhon, N., Martin-Denavit, T., Thomas, L., Andry-Benzaquen, P., Dupin, N.,

508 Boitier, F., Rossi, A., Perrot, J.-L., Labeille, B., Robert, C., Escudier, B., Caron, O., Brugières, L.,

509 Saule, S., Gardie, B., Gad, S., Richard, S., Couturier, J., Teh, B. T., Ghiorzo, P., Pastorino, L., 
510 Puig, S., Badenas, C., Olsson, H., Ingvar, C., Rouleau, E., Lidereau, R., Bahadoran, P., Vielh, P., 511 Corda, E., Blanché, H., Zelenika, D., Galan, P., Aubin, F., Bachollet, B., Becuwe, C., Berthet, P., 512 Jean Bignon, Y., Bonadona, V., Bonafe, J.-L., Bonnet-Dupeyron, M.-N., Cambazard, F.,

513 Chevrant-Breton, J., Coupier, I., Dalac, S., Demange, L., d'Incan, M., Dugast, C., Faivre, L.,

514 Vincent-Fétita, L., Gauthier-Villars, M., Gilbert, B., Grange, F., Grob, J.-J., Humbert, P., Janin, N., 515 Joly, P., Kerob, D., Lasset, C., Leroux, D., Levang, J., Limacher, J.-M., Livideanu, C., Longy, M., 516 Lortholary, A., Stoppa-Lyonnet, D., Mansard, S., Mansuy, L., Marrou, K., Matéus, C., Maugard, 517 C., Meyer, N., Nogues, C., Souteyrand, P., Venat-Bouvet, L., Zattara, H., Chaudru, V., Lenoir, 518 G. M., Lathrop, M., Davidson, I., Avril, M.-F., Demenais, F., Ballotti, R. and Bressac-de 519 Paillerets, B. (2011) 'A SUMOylation-defective MITF germline mutation predisposes to

520

521

522

523

524

525

526

527 melanoma and renal carcinoma', Nature. Nature Publishing Group, 480(7375), pp. 94-98. doi: 10.1038/nature10539.

528

529

530

Beuret, L., Ohanna, M., Strub, T., Allegra, M., Davidson, I., Bertolotto, C. and Ballotti, R. (2011) 'BRCA1 is a new MITF target gene', Pigment Cell \& Melanoma Research, 24(4), pp. 725-727. doi: 10.1111/j.1755-148X.2011.00862.x.

Carreira, S., Goodall, J., Aksan, I., La Rocca, S. A., Galibert, M.-D., Denat, L., Larue, L. and Goding, C. R. (2005) 'Mitf cooperates with Rb1 and activates p21Cipl expression to regulate cell cycle progression', Nature, 433(7027), pp. 764-769. doi: 10.1038/nature03269.

531

532

533

534

Carreira, S., Goodall, J., Denat, L., Rodriguez, M., Nuciforo, P., Hoek, K. S., Testori, A., Larue, L. and Goding, C. R. (2006) 'Mitf regulation of Dial controls melanoma proliferation and invasiveness', Genes \& development, 20(24), pp. 3426-3439. doi: 10.1101/gad.406406.

Cheli, Y., Giuliano, S., Fenouille, N., Allegra, M., Hofman, V., Hofman, P., Bahadoran, P., Lacour, J.-P., Tartare-Deckert, S., Bertolotto, C. and Ballotti, R. (2011) 'Hypoxia and MITF control metastatic behaviour in mouse and human melanoma cells', Oncogene. Nature Publishing Group, 31(19), pp. 2461-2470. doi: 10.1038/onc.2011.425.

535

536

537

Cheli, Y., Guiliano, S., Botton, T., Rocchi, S., Hofman, V., Hofman, P., Bahadoran, P., Bertolotto, C. and Ballotti, R. (2011) 'Mitf is the key molecular switch between mouse or human melanoma initiating cells and their differentiated progeny', Oncogene. Nature Publishing

538

539

540

541

542

543

544

545

546

547 Group, 30(20), pp. 2307-2318. doi: 10.1038/onc.2010.598.

Davies, H., Bignell, G. R., Cox, C., Stephens, P., Edkins, S., Clegg, S., Teague, J., Woffendin, H., Garnett, M. J., Bottomley, W., Davis, N., Dicks, E., Ewing, R., Floyd, Y., Gray, K., Hall, S., Hawes, R., Hughes, J., Kosmidou, V., Menzies, A., Mould, C., Parker, A., Stevens, C., Watt, S., Hooper, S., Wilson, R., Jayatilake, H., Gusterson, B. A., Cooper, C., Shipley, J., Hargrave, D., Pritchard-Jones, K., Maitland, N., Chenevix-Trench, G., Riggins, G. J., Bigner, D. D., Palmieri, G., Cossu, A., Flanagan, A., Nicholson, A., Ho, J. W. C., Leung, S. Y., Yuen, S. T., Weber, B. L., Seigler, H. F., Darrow, T. L., Paterson, H., Marais, R., Marshall, C. J., Wooster, R., Stratton, M. R. and Futreal, P. A. (2002) 'Mutations of the BRAF gene in human cancer', Nature. Nature Publishing Group, 417(6892), pp. 949-954. doi: 10.1038/nature00766.

548

549

550

551

Garraway, L. A., Widlund, H. R., Rubin, M. A., Getz, G., Berger, A. J., Ramaswamy, S., Beroukhim, R., Milner, D. A., Granter, S. R., Du, J., Lee, C., Wagner, S. N., Li, C., Golub, T. R., Rimm, D. L., Meyerson, M. L., Fisher, D. E. and Sellers, W. R. (2005) 'Integrative genomic analyses identify MITF as a lineage survival oncogene amplified in malignant melanoma',

552

553

554

555

556 Nature, 436(7047), pp. 117-122. doi: 10.1038/nature03664.

Giuliano, S., Cheli, Y., Ohanna, M., Bonet, C., Beuret, L., Bille, K., Loubat, A., Hofman, V., Hofman, P., Ponzio, G., Bahadoran, P., Ballotti, R. and Bertolotto, C. (2010) 'Microphthalmiaassociated transcription factor controls the DNA damage response and a lineage-specific senescence program in melanomas.', Cancer research, 70(9), pp. 3813-3822. doi:

557 10.1158/0008-5472.CAN-09-2913. 
558 Goding, C. R. (2013) 'Fishful thinking: the rise and fall of MITF in melanoma', Pigment Cell \& 559 Melanoma Research, 27(1), pp. 7-8. doi: 10.1111/pcmr.12177.

560 Greshock, J., Bachman, K. E., Degenhardt, Y. Y., Jing, J., Wen, Y. H., Eastman, S., McNeil, E., 561 Moy, C., Wegrzyn, R., Auger, K., Hardwicke, M. A. and Wooster, R. (2010) 'Molecular target 562 class is predictive of in vitro response profile.', Cancer research, 70(9), pp. 3677-3686. doi: 563 10.1158/0008-5472.CAN-09-3788.

564 Haqq, C., Nosrati, M., Sudilovsky, D., Crothers, J., Khodabakhsh, D., Pulliam, B. L., Federman, 565 S., Miller, J. R., Allen, R. E., Singer, M. I., Leong, S. P. L., Ljung, B.-M., Sagebiel, R. W. and 566 Kashani-Sabet, M. (2005) 'The gene expression signatures of melanoma progression', 567 Proceedings of the National Academy of Sciences of the United States of America, 102(17), 568 pp. 6092-6097. doi: 10.1073/pnas.0501564102.

569 Harbst, K., Staaf, J., Lauss, M., Karlsson, A., Masback, A., Johansson, I., Bendahl, P.-O., Vallon570 Christersson, J., Torngren, T., Ekedahl, H., Geisler, J., Höglund, M., Höglund, M., Ringnér, M., 571 Ringnér, M., Lundgren, L., Jirström, K., Olsson, H., Ingvar, C., Borg, A., Tsao, H. and Jönsson, G. 572 (2012) 'Molecular profiling reveals low- and high-grade forms of primary melanoma.', Clinical 573 cancer research : an official journal of the American Association for Cancer Research, 18(15), 574 pp. 4026-4036. doi: 10.1158/1078-0432.CCR-12-0343.

575 Hoek, K. S. and Goding, C. R. (2010) 'Cancer stem cells versus phenotype-switching in 576 melanoma', Pigment Cell \& Melanoma Research, 23(6), pp. 746-759. doi: 10.1111/j.1755577 148X.2010.00757.x.

578 Hoek, K. S., Eichhoff, O. M., Schlegel, N. C., Döbbeling, U., Kobert, N., Schaerer, L., Hemmi, S. 579 and Dummer, R. (2008) 'In vivo switching of human melanoma cells between proliferative 580 and invasive states', Cancer research, 68(3), pp. 650-656. doi: 10.1158/0008-5472.CAN-075812491.

582 Hoek, K. S., Schlegel, N. C., Brafford, P., Sucker, A., Ugurel, S., Kumar, R., Weber, B. L., 583 Nathanson, K. L., Phillips, D. J., Herlyn, M., Schadendorf, D. and Dummer, R. (2006) 584 'Metastatic potential of melanomas defined by specific gene expression profiles with no BRAF 585 signature', Pigment cell research / sponsored by the European Society for Pigment Cell 586 Research and the International Pigment Cell Society, 19(4), pp. 290-302. doi:

587 10.1111/j.1600-0749.2006.00322.x.

588 Hoek, K. S., Schlegel, N. C., Eichhoff, O. M., Widmer, D. S., (null), (null), (null), (null), 589 Schepsky, A., Dummer, R. and Steingrimsson, E. (2008) 'Novel MITF targets identified using a 590 two-step DNA microarray strategy', Pigment Cell \& Melanoma Research, 21(6), pp. 665-676. 591 doi: 10.1111/j.1755-148X.2008.00505.x.

592 Huang, D. W., Sherman, B. T., Tan, Q., Kir, J., Liu, D., Bryant, D., Guo, Y., Stephens, R., Baseler, 593

594 595 M. W., Lane, H. C. and Lempicki, R. A. (2007) 'DAVID Bioinformatics Resources: expanded annotation database and novel algorithms to better extract biology from large gene lists', Nucleic Acids Research, 35(Web Server), pp. W169-W175. doi: 10.1093/nar/gkm415.

601 Johansson, P., Pavey, S. and Hayward, N. (2007) 'Confirmation of a BRAF mutation-associated 602 gene expression signature in melanoma', Pigment cell research / sponsored by the European 603 Society for Pigment Cell Research and the International Pigment Cell Society, 20(3), pp. 216604 221. doi: 10.1111/j.1600-0749.2007.00375.x. 
605 Jonsson, G., Busch, C., Knappskog, S., Geisler, J., Miletic, H., Ringner, M., Lillehaug, J. R., Borg, 606 A. and Lonning, P. E. (2010) 'Gene Expression Profiling-Based Identification of Molecular 607 Subtypes in Stage IV Melanomas with Different Clinical Outcome', Clinical Cancer Research, 608 16(13), pp. 3356-3367. doi: 10.1158/1078-0432.CCR-09-2509.

609 Levy, C. (2001) 'A New Role for the STAT3 Inhibitor, PIAS3. A REPRESSOR OF

610 MICROPHTHALMIA TRANSCRIPTION FACTOR', Journal of Biological Chemistry, 277(3), pp.

611 1962-1966. doi: 10.1074/jbc.M109236200.

612 Levy, C., Khaled, M. and Fisher, D. E. (2006) 'MITF: master regulator of melanocyte

613 development and melanoma oncogene', Trends in Molecular Medicine, 12(9), pp. 406-414.

614 doi: 10.1016/j.molmed.2006.07.008.

615 Loercher, A., Tank, E., Delston, R. and Harbour, J. (2005) 'MITF links differentiation with cell

616 cycle arrest in melanocytes by transcriptional activation of INK4A', The Journal of cell biology,

617 168(1), pp. 35-40. doi: 10.1083/jcb.200410115.

618 McGill, G. G., Haq, R., Nishimura, E. K. and Fisher, D. E. (2006) 'c-Met Expression Is Regulated 619 by Mitf in the Melanocyte Lineage', Journal of Biological Chemistry, 281(15), pp. 10365-

620 10373. doi: 10.1074/jbc.M513094200.

621 Nair, S. S., Chaubal, V. A., Shioda, T., Coser, K. R. and Mojamdar, M. (2001) 'Over-expression 622 of MSG1 Transcriptional Co-activator Increases Melanin in B16 Melanoma Cells: A Possible 623 Role for MSG1 in Melanogenesis', Pigment cell research / sponsored by the European Society 624 for Pigment Cell Research and the International Pigment Cell Society. Wiley Online Library, 625 14(3), pp. 206-209. doi: 10.1034/j.1600-0749.2001.140311.x.

626 Pierrat, M. J., Marsaud, V., Mauviel, A. and Javelaud, D. (2012) 'Expression of Microphthalmia-

627

628

629 associated Transcription Factor (MITF), Which Is Critical for Melanoma Progression, Is Inhibited by Both Transcription Factor GLI2 and Transforming Growth Factor- ', The Journal of biological chemistry, 287(22), pp. 17996-18004. doi: 10.1074/jbc.M112.358341.

630 Pinner, S., Jordan, P., Sharrock, K., Bazley, L., Collinson, L., Marais, R., Bonvin, E., Goding, C.

631 and Sahai, E. (2009) 'Intravital Imaging Reveals Transient Changes in Pigment Production and 632 Brn2 Expression during Metastatic Melanoma Dissemination', Cancer research, 69(20), pp.

633 7969-7977. doi: 10.1158/0008-5472.CAN-09-0781.

634 Plisov, S. (2005) 'Cited1 Is a Bifunctional Transcriptional Cofactor That Regulates Early 635 Nephronic Patterning', Journal of the American Society of Nephrology, 16(6), pp. 1632-1644. 636 doi: 10.1681/ASN.2004060476.

637 Ryu, B., Kim, D. S., Deluca, A. M. and Alani, R. M. (2007) 'Comprehensive expression profiling 638 of tumor cell lines identifies molecular signatures of melanoma progression', PLoS ONE, 2(7), 639 p. e594. doi: 10.1371/journal.pone.0000594.

640 Saeed, A. I., Bhagabati, N. K., Braisted, J. C., Liang, W., Sharov, V., Howe, E. A., Li, J.,

641 Thiagarajan, M., White, J. A. and Quackenbush, J. (2006) '[9] TM4 Microarray Software Suite',

642 in Methods in Enzymology. Elsevier (Methods in Enzymology), pp. 134-193. doi:

643 10.1016/S0076-6879(06)11009-5.

644 Sáez-Ayala, M., Montenegro, M. F., Sánchez-del-Campo, L., Fernández-Pérez, M. P., Chazarra, 645 S., Freter, R., Middleton, M., Piñero-Madrona, A., Cabezas-Herrera, J., Goding, C. R. and 646 Rodríguez-López, J. N. (2013) 'Directed Phenotype Switching as an Effective Antimelanoma 647 Strategy', Cancer Cell, 24(1), pp. 105-119. doi: 10.1016/j.ccr.2013.05.009.

648 Sánchez-Martín, M., Rodríguez-García, A., Pérez-Losada, J., Sagrera, A., Read, A. P. and 649 Sánchez-García, I. (2002) 'SLUG (SNAI2) deletions in patients with Waardenburg disease', 
650 Human molecular genetics, 11(25), pp. 3231-3236.

651 Sestáková, B., Ondrusová, L. and Vachtenheim, J. (2010) 'Cell cycle inhibitor p21/ WAF1/ CIP1

652 as a cofactor of MITF expression in melanoma cells', Pigment Cell \& Melanoma Research,

653 23(2), pp. 238-251. doi: 10.1111/j.1755-148X.2010.00670.x.

654 Shioda, T., Fenner, M. H. and Isselbacher, K. J. (1996) 'msg1, a novel melanocyte-specific

655 gene, encodes a nuclear protein and is associated with pigmentation', Proceedings of the

656 National Academy of Sciences of the United States of America, 93(22), pp. 12298-12303.

657 Shioda, T., Lechleider, R. J., Dunwoodie, S. L., Li, H., Yahata, T., de Caestecker, M. P., Fenner,

658 M. H., Roberts, A. B. and Isselbacher, K. J. (1998) 'Transcriptional activating activity of Smad4:

659 Roles of SMAD hetero-oligomerization and enhancement by an associating transactivator',

660 Proceedings of the National Academy of Sciences of the United States of America, 95(17), p.

6619785.

662 Smith, A. P., Hoek, K. and Becker, D. (2005) 'Whole-genome expression profiling of the

663 melanoma progression pathway reveals marked molecular differences between

664 nevi/melanoma in situ and advanced-stage melanomas', Cancer Biology \& Therapy, 4(9), pp.

665 1018-1029.

666 Strub, T., Giuliano, S., Ye, T., Bonet, C., Keime, C., Kobi, D., Le Gras, S., Cormont, M., Ballotti, 667 R., Bertolotto, C. and Davidson, I. (2011) 'Essential role of microphthalmia transcription factor

668 for DNA replication, mitosis and genomic stability in melanoma', Oncogene, 30(20), pp.

669 2319-2332. doi: 10.1038/onc.2010.612.

670 Talantov, D. (2005) 'Novel Genes Associated with Malignant Melanoma but not Benign

671 Melanocytic Lesions', Clinical Cancer Research, 11(20), pp. 7234-7242. doi: 10.1158/1078-

672 0432.CCR-05-0683.

673 Vachtenheim, J., Šestáková, B. and Tuháčková, Z. (2007) 'Inhibition of MITF transcriptional

674 activity independent of targeting p300/CBP coactivators', Pigment cell research / sponsored

675 by the European Society for Pigment Cell Research and the International Pigment Cell

676 Society, 20(1), pp. 41-51. doi: 10.1111/j.1600-0749.2006.00354.x.

677 Vallon-Christersson, J., Nordborg, N., Svensson, M. and Häkkinen, J. (2009) ‘BASE--2nd

678 generation software for microarray data management and analysis', BMC bioinformatics, 10,

679 p. 330. doi: 10.1186/1471-2105-10-330.

680 Wellbrock, C., Rana, S., Paterson, H., Pickersgill, H., Brummelkamp, T. and Marais, R. (2008)

681 'Oncogenic BRAF regulates melanoma proliferation through the lineage specific factor MITF',

682 PLOS ONE, 3(7), p. e2734. doi: 10.1371/journal.pone.0002734.

683 Widlund, H. R. and Fisher, D. E. (2003) 'Microphthalamia-associated transcription factor: a 684 critical regulator of pigment cell development and survival', Oncogene, 22(20), pp. 3035-

685 3041. doi: 10.1038/sj.onc.1206443.

686 Widmer, D. S., Cheng, P. F., Eichhoff, O. M., Belloni, B. C., Zipser, M. C., Schlegel, N. C.,

687 Javelaud, D., Mauviel, A., Dummer, R. and Hoek, K. S. (2012) 'Systematic classification of

688 melanoma cells by phenotype-specific gene expression mapping.', Pigment Cell \& Melanoma

689 Research, 25(3), pp. 343-353. doi: 10.1111/j.1755-148X.2012.00986.x.

690 Yahata, T., de Caestecker, M. P., Lechleider, R. J., Andriole, S., Roberts, A. B., Isselbacher, K. J.

691 and Shioda, T. (2000) 'The MSG1 non-DNA-binding transactivator binds to the p300/CBP

692 coactivators, enhancing their functional link to the Smad transcription factors.', The Journal

693 of biological chemistry, 275(12), pp. 8825-8834. doi: 10.1074/jbc.275.12.8825. 
694 Yahata, T., Shao, W., Endoh, H., Hur, J., Coser, K. R., Sun, H., Ueda, Y., Kato, S., Isselbacher, K. 695 J., Brown, M. and Shioda, T. (2001) 'Selective coactivation of estrogen-dependent

696 transcription by CITED1 CBP/p300-binding protein.', Genes \& development, 15(19), pp. 2598-

697 2612. doi: 10.1101/gad.906301.

698 Yan, G., Eller, M. S., Elm, C., Larocca, C. A., Ryu, B., Panova, I. P., Dancy, B. M., Bowers, E. M., 699 Meyers, D., Lareau, L., Cole, P. A., Taverna, S. D. and Alani, R. M. (2013) 'Selective inhibition 700 of p300 HAT blocks cell cycle progression, induces cellular senescence, and inhibits the DNA 701 damage response in melanoma cells.', Journal of Investigative Dermatology, 133(10), pp.

702 2444-2452. doi: 10.1038/jid.2013.187.

703 Yokoyama, S. and Fisher, D. E. (2011) 'Transcriptional Regulation in Melanoma', in Bosserhoff, 704 A. (ed.) Melanoma Development. SpringerWeinNewYork, p. 376.

705 Yokoyama, S., Woods, S. L., Boyle, G. M., Aoude, L. G., MacGregor, S., Zismann, V., Gartside, 706 M., Cust, A. E., Haq, R., Harland, M., Taylor, J. C., Duffy, D. L., Holohan, K., Dutton-Regester, 707 K., Palmer, J. M., Bonazzi, V., Stark, M. S., Symmons, J., Law, M. H., Schmidt, C., Lanagan, C., 708 O'Connor, L., Holland, E. A., Schmid, H., Maskiell, J. A., Jetann, J., Ferguson, M., Jenkins, M. A., 709 Kefford, R. F., Giles, G. G., Armstrong, B. K., Aitken, J. F., Hopper, J. L., Whiteman, D. C.,

710 Pharoah, P. D., Easton, D. F., Dunning, A. M., Newton-Bishop, J. A., Montgomery, G. W., Martin, 711 N. G., Mann, G. J., Bishop, D. T., Tsao, H., Trent, J. M., Fisher, D. E., Hayward, N. K. and Brown, 712 K. M. (2011) 'A novel recurrent mutation in MITF predisposes to familial and sporadic 713 melanoma', Nature. Nature Publishing Group, 480(7375), pp. 99-103. doi:

714 10.1038/nature10630. 
1

TGF $\beta$ induced gene expression in A2058 melanoma cells

(a) Distribution of the proliferative and invasive signature score genes relative to the heatmap of gene expression changes induced by TGF $\beta$ treatment. Vertical lanes in the hierarchical cluster represent TGF $\beta$ treated or untreated replicates in the SAM 2-group comparison b) Gene expression heatmap of the proliferative and invasive signature within those genes significantly altered by TGF $\beta$ treatment (1009 transcripts following SAM, median FDR q-value $=1 \%$, the full list can be found in S7). '2006' refers to the original signature list (motif1 and motif2, see Hoek et al. 2006) while '2012' refers to the updated signature derived from further datasets (Widmer et al. 2012). These lists can also be found in supplementary data S9. (c) Western blot of MITF and CITED showing both proteins are suppressed by TGF $\beta$ treatment. $\beta$-Actin is used as a loading control. 
a

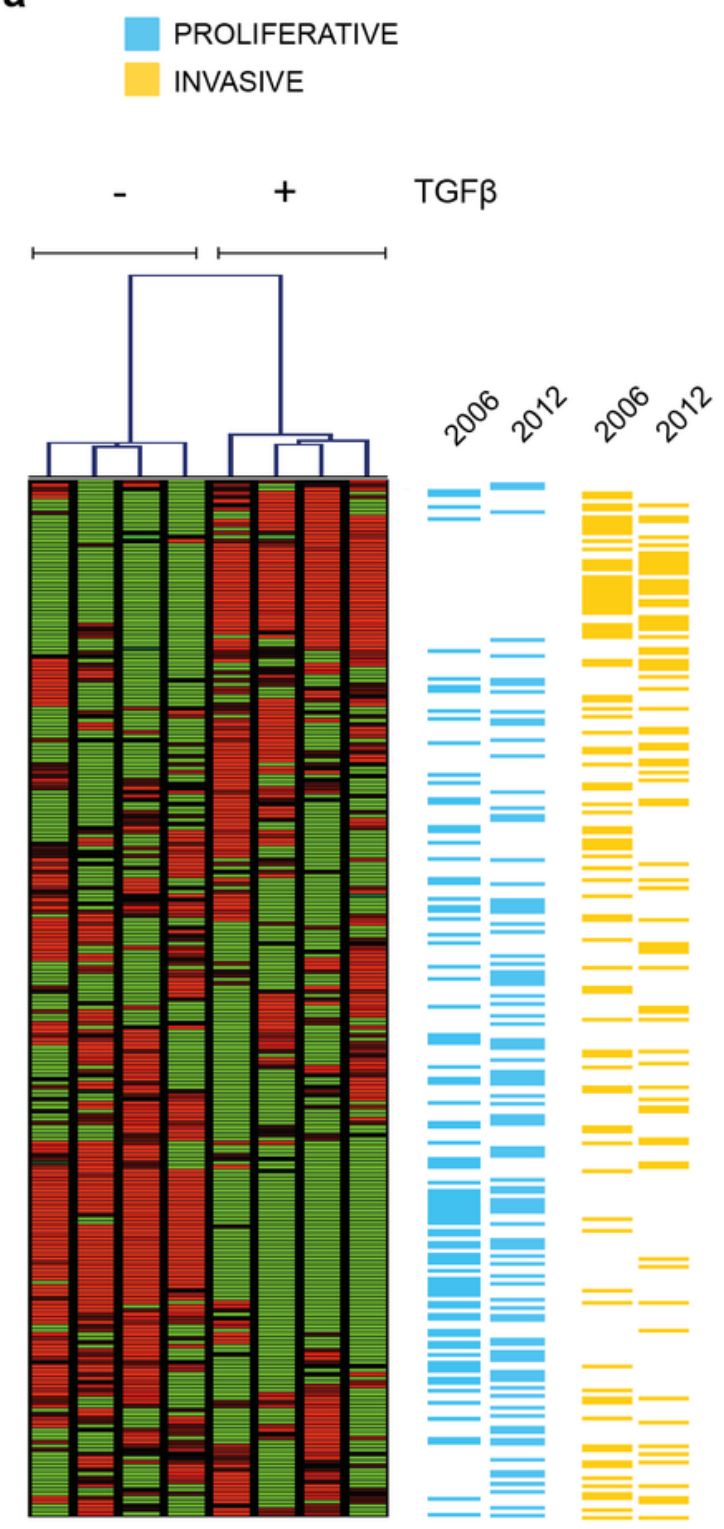

b

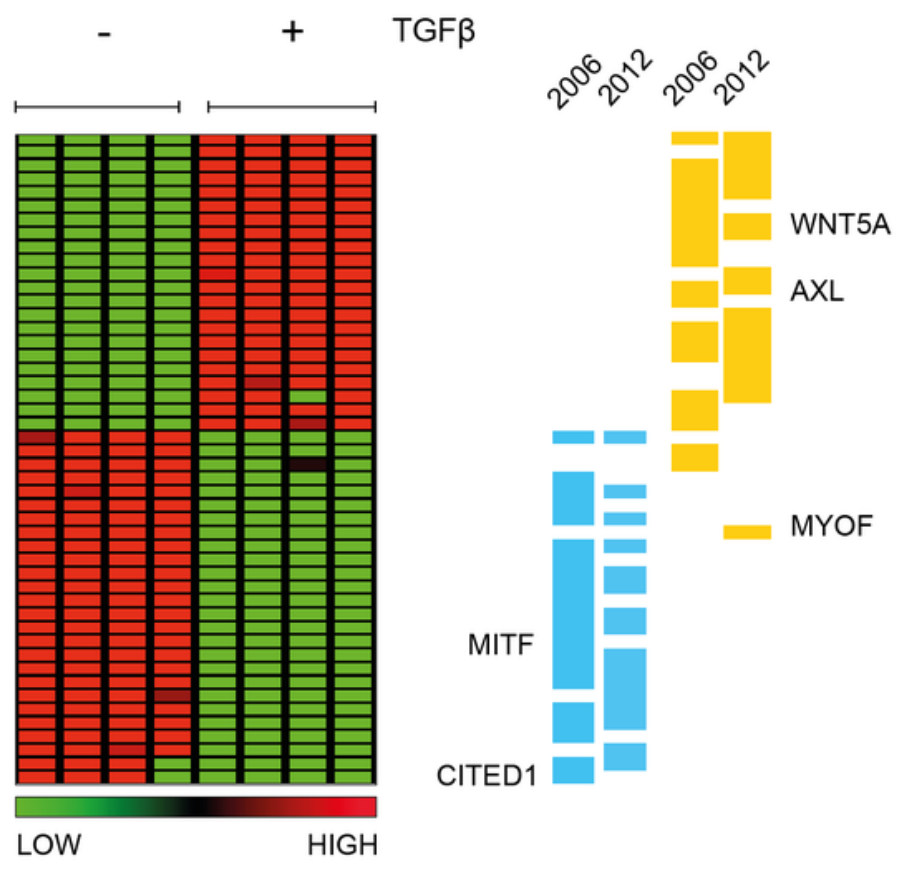

C

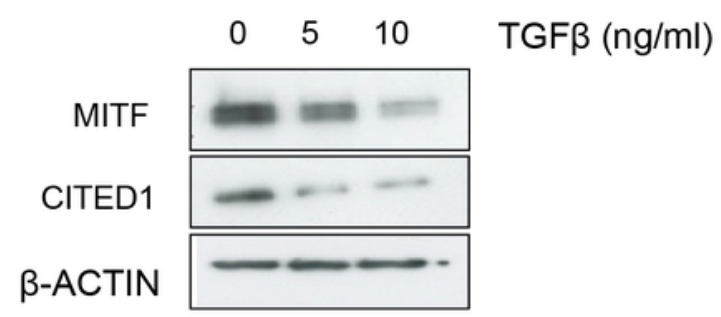




\section{2}

\section{CITED1 expression correlates with MITF expression}

(a) The relative MITF and CITED1 expression levels from the publicly available gene expression data of 120 melanoma cell lines (Pearson correlation $r=0.6543, p<0.001$ ). The full list of cells lines and expression data can be found in S10. Arrows indicate the cell lines used in this study. The cell lines are further subdivided into one of either 'invasive' of 'proliferative' phenotype based on expression signature score. (b) A Western blot is shown of the relative protein expression levels of both MITF and CITED1 in our cell lines in good agreement with the transcript levels.

a

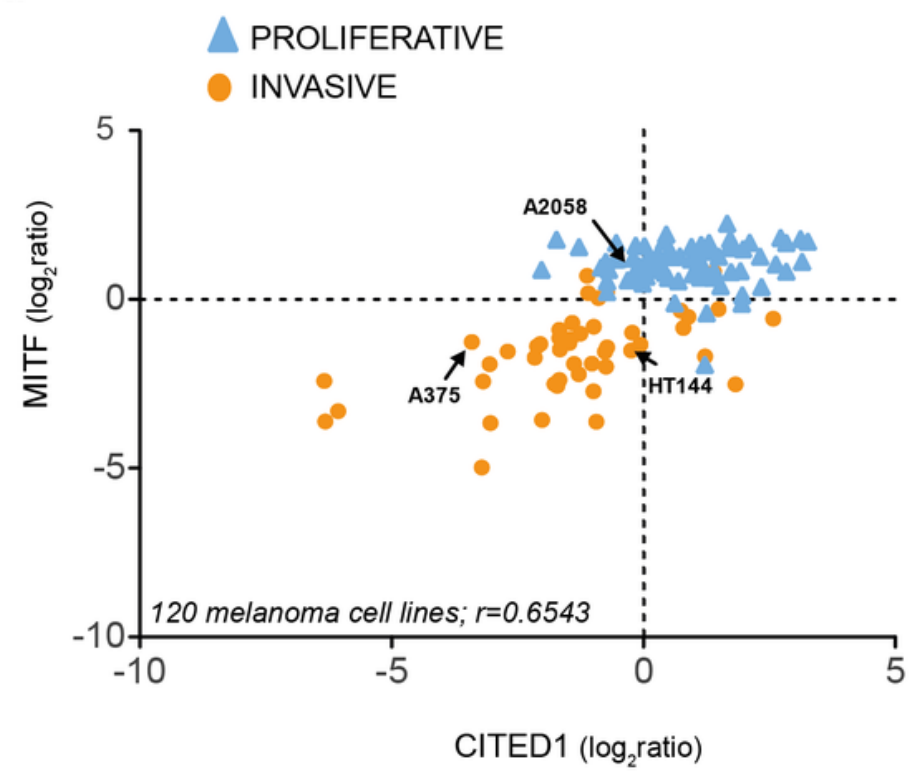

b

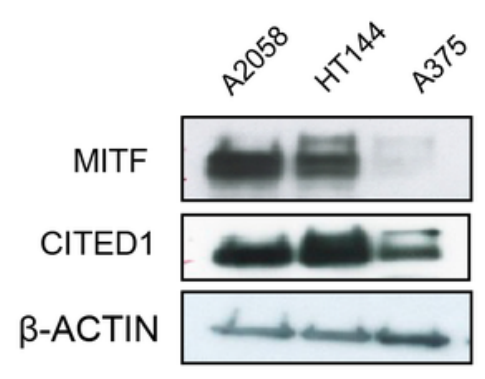




\section{3}

CITED1 silencing induces a phenotype switch

(a) 120 melanoma cell lines are shown distributed on the basis of the phenotype score. The HT144 cells chosen to study the effects of CITED1 downregulation are indicated. (b) Following CITED1 downregulation a phenotype shift is observed indicated by their scatter position change according to the average expression score of genes that distinguish invasive from proliferative phenotype. For the 120 melanoma cell lines (Affymetrix platform) the expression score was derived from expression levels of 50 and 54 proliferative and invasive genes with matching genes symbols, respectively, while for the HT144 experiment (Illumina platform), 51 and 54 proliferative and invasive genes with matching genes symbols were retrieved. A Western blot of the degree of protein downregulation of CITED1 at the time of the expression analysis is also shown. $\beta$-Actin is used as a loading control (inset). (c) A heatmap comprising the 'invasive' and 'proliferative' signature genes illustrating how they are altered by CITED1 silencing; \#1 and \#3 denote two separate siRNAs targeting CITED1 and the vertical lanes represent the 4 replicates per treatment. 
a

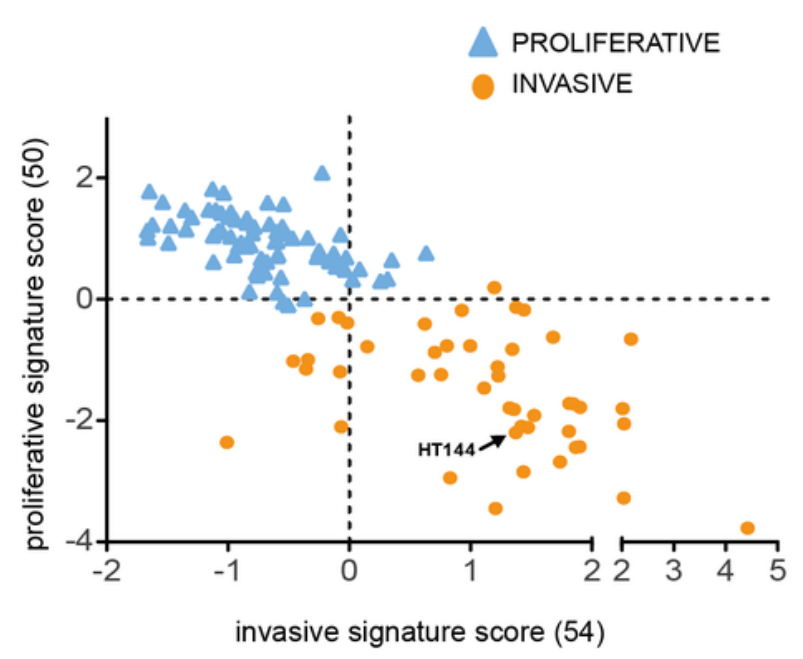

C
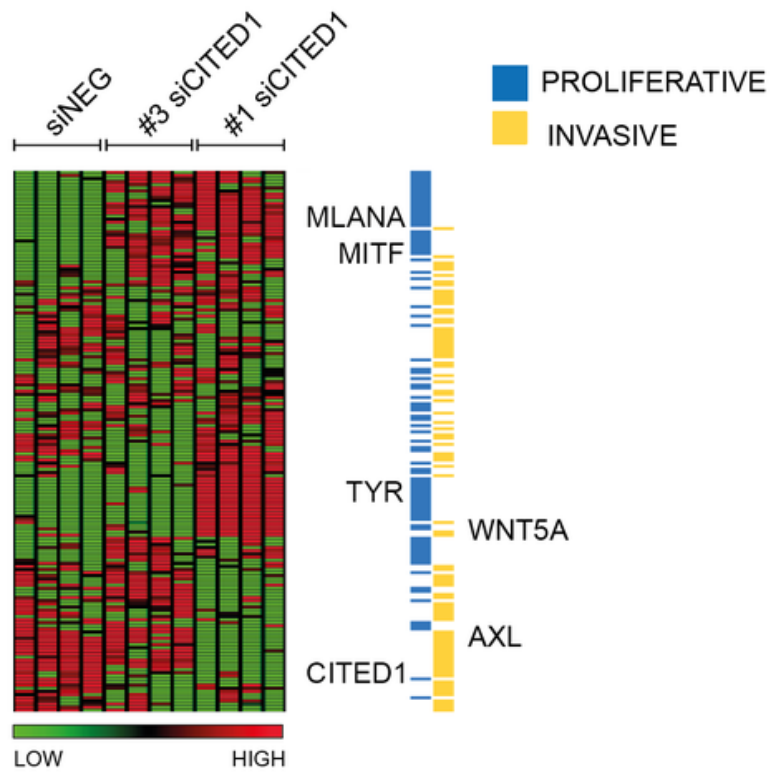

b

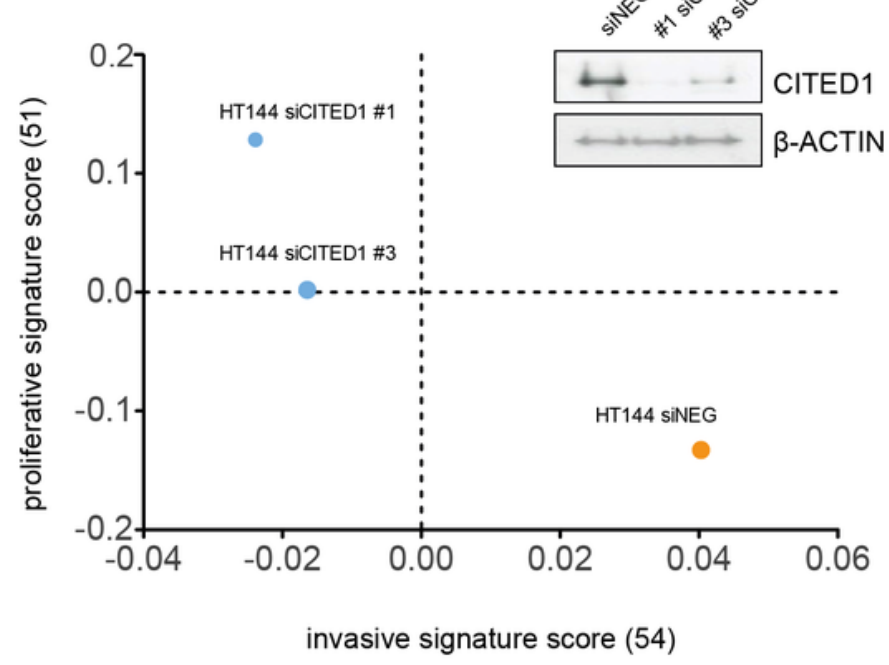




\section{4}

CITED1 regulates MITF and its targets genes

(a) A heatmap showing the 312 transcripts identified as significantly changed using a SAM 2way comparison between siNEG and siCITED1 (\#1\&\#3 were combined), median FDR qvalue $=3 \%$. The four replicates from each condition, siNEG and, siCITED1\#1 and SICITED1\#3, respectively, group together in the hierarchical cluster shown. The full list of genes can be found in S8. MITF, as well as a cohort of significantly enriched MITF targets, genes associated with pigmentation, and genes involved in the UV/DNA damage response are highlighted on the right. (b) Western blot confirmation of the effect of silencing CITED1, using siRNA (\#1, \#3) relative to a negative control siRNA (N), on MITF protein expression in HT144 cells at 24 and 48 hours post-transfection, and the effect of overexpressing CITED1 (pCITED1) relative to an empty vector control (EV) in A2058 cells at 24 hours post-transfection. $\beta$-Actin is used as a loading control in each case. (c) Western blot showing the effect of silencing MITF using two siRNAs (siM1, siM3) on both MITF and CITED1 levels in HT144 cells at 48 hours posttransfection relative to a negative control siRNA (N). $\beta$-Actin is used as a loading control. 
a

MITF TARGETS

DNA DAMAGE RESPONSE

PIGMENTATION
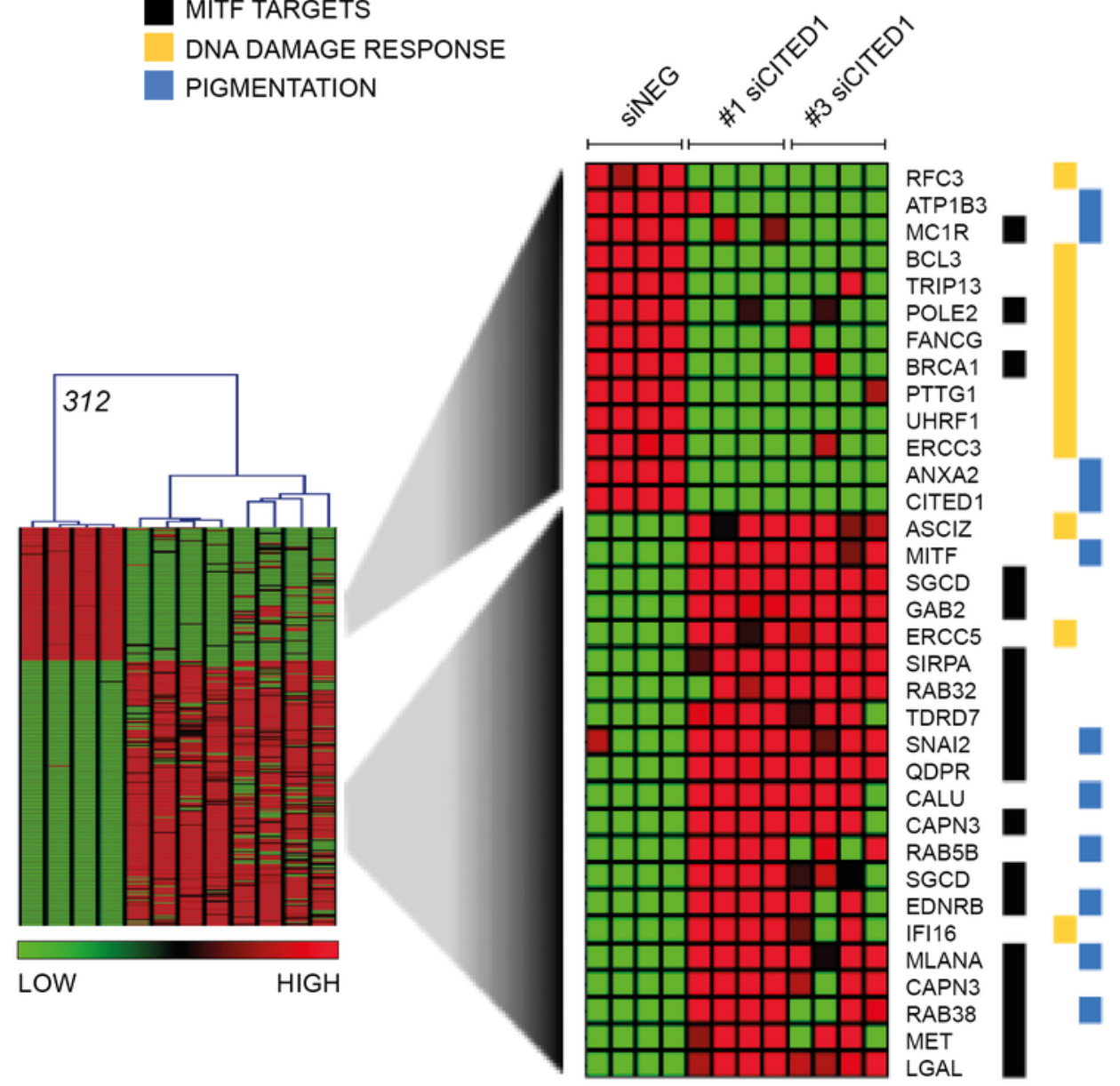

b

C
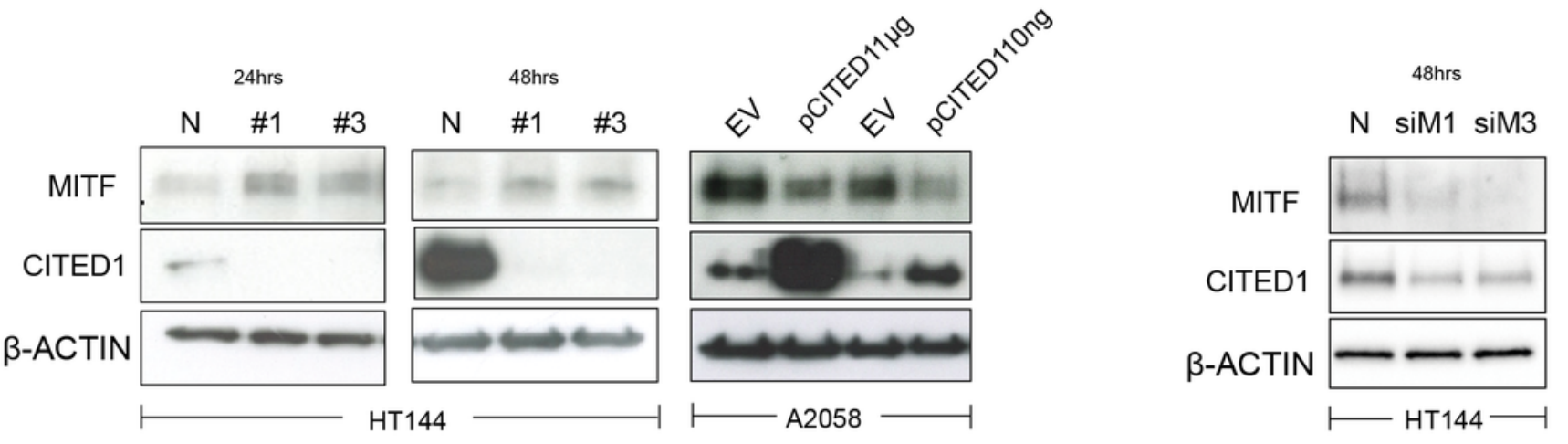


\section{5}

CITED1 silencing restrains cell cycle progression and reduces cell viability

(a) A bar chart showing the \% change in cell cycle distribution in \#1 siCITED1 treated HT144 cells relative to siNEG treated HT144 cells. The reduction in the total S-phase is shown at 33 hours, 48 hours and 72 hours post-transfection in addition to the corresponding increase in the diploid G1 fraction. (b) Western blots showing upregulation of CDKN1A/P21 following CITED1 silencing in HT144 cells and suppression of CDKN1C/P57 following CITED1 overexpression in A2058 cells. (c) An Alamar Blue based metabolic assay shows a reduction in cell viability over 5 days in HT144 cells treated with siCITED1 relative to those treated with siNEG. Stars indicate significance for siNEG vs. \#1 siCITED1 where ${ }^{* *} \mathrm{p}<=0.0005,{ }^{*} \mathrm{p}<=$ 0.005 and $* p<=0.05$. In the case of siNEG vs. \#1 siCITED1, the difference is significant $(*)$ at 96 and 120 hours. 
a

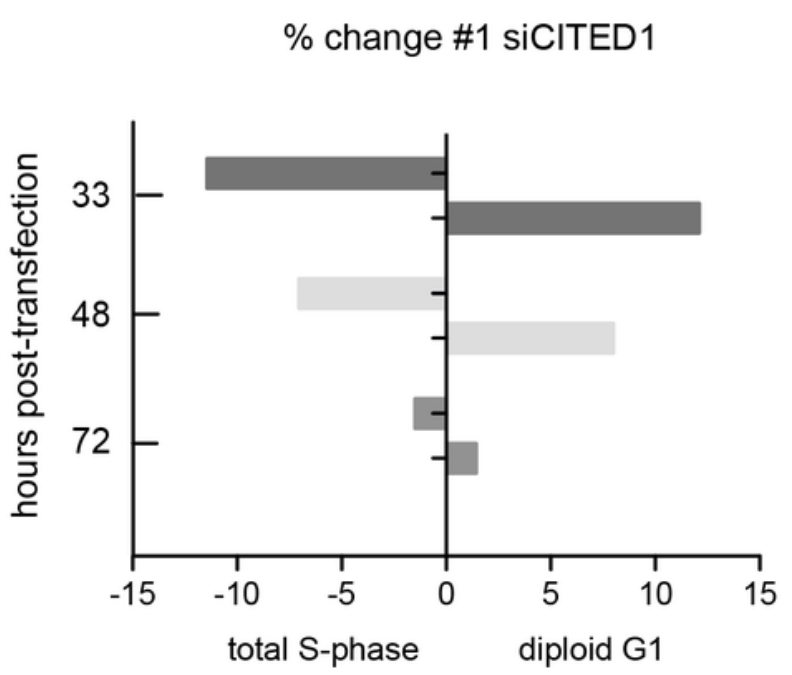

C

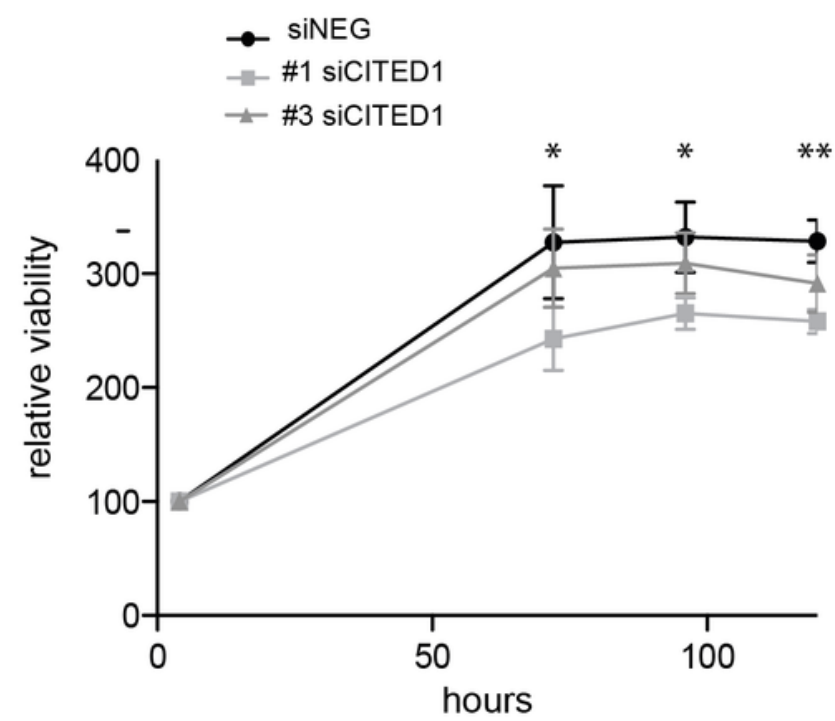

b
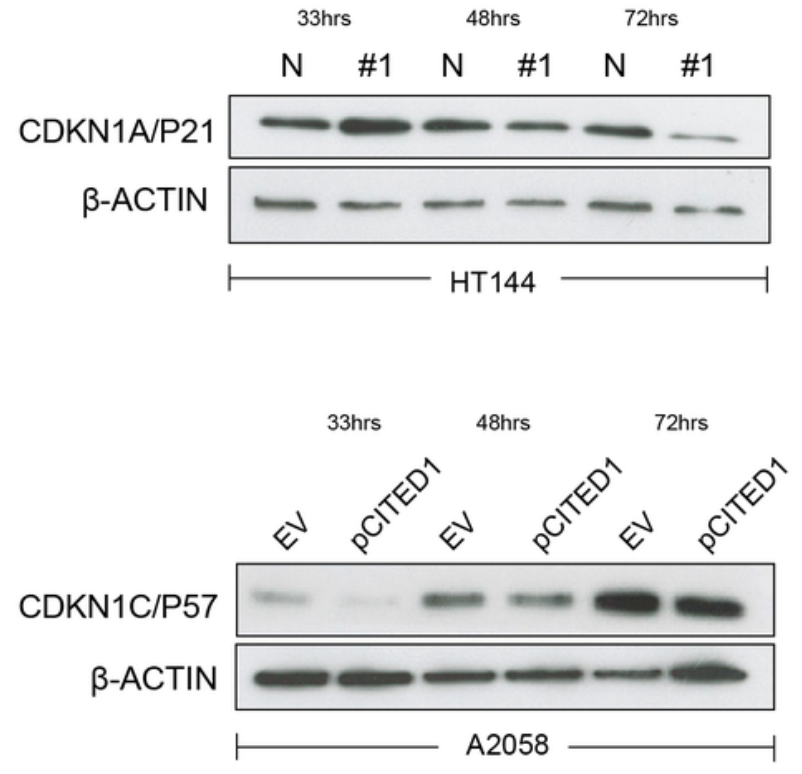
6

CITED1 silencing transiently upregulates MITF via promoter activation

(a) A Western blot of HT144 cell lysate samples taken at the indicated time points posttransfection and showing the corresponding levels of MITF protein in \#1 siCITED1 and siNEG treated cells. Shown underneath are the changes in mRNA levels of MITF-M, CITED1 and a housekeeper gene IPO8, as measured by specific ddPCR assays over a time course of 4-100 hours following transfection of HT144 cells with either siCITED1 or siNEG. (b) A Western blot of A2058 cell lysate samples taken at the indicated time points post-transfection and showing the corresponding levels of MITF protein between CITED1 overexpression (pCITED1) and empty vector (EV) control. Shown underneath are the changes in mRNA levels of MITF and a housekeeper gene IPO8, as measured by specific ddPCR assays over a time course of 33-72 hours following transfection of A2058 with either PCITED1 or an empty vector control.

(c) The relative luciferase activity of the MITF-M promoter reporter measured in lysates of A375 cells transfected with the PCITED1 expression plasmid or empty vector (EV) control and treated with or without TGF $\beta$ for 24 hours $(* * * p<=0.0005, * * p<=0.005$ and NS $=$ not significant). 
a
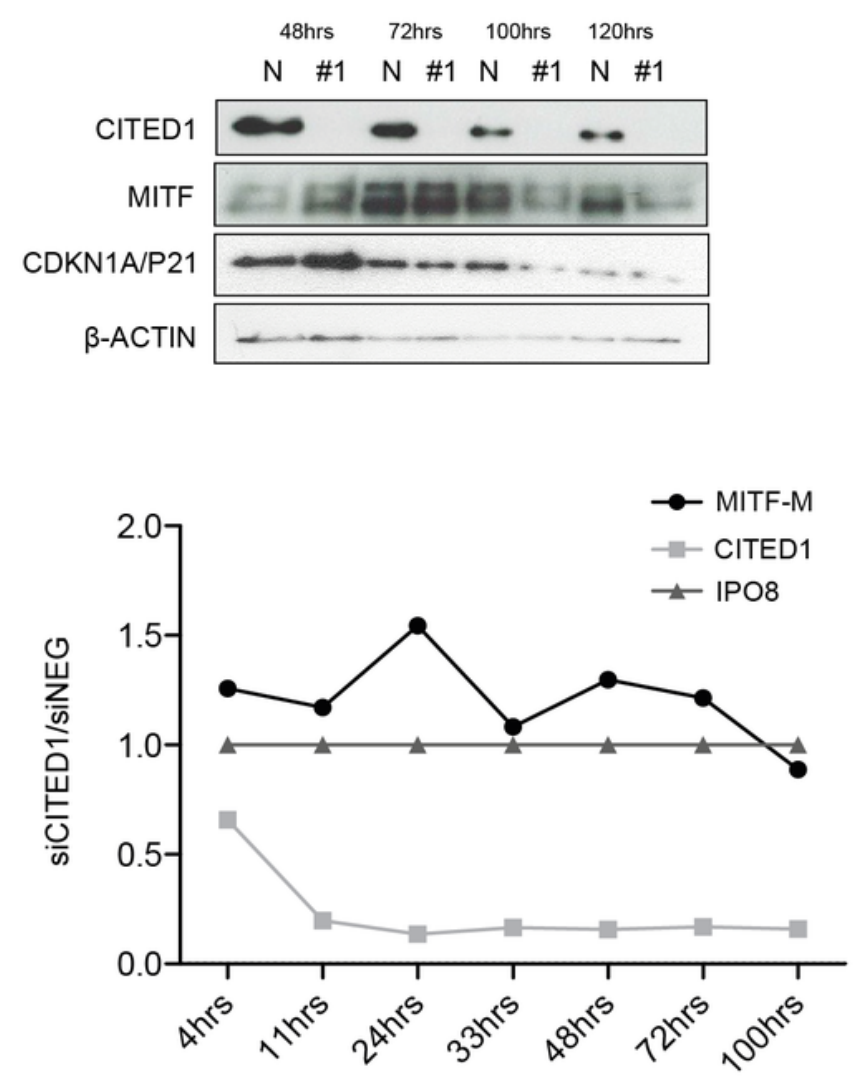

C

Empty vector

pCITED1

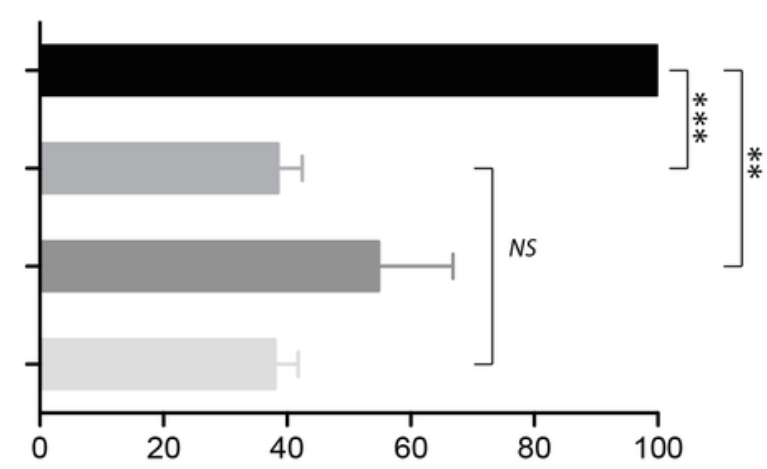

$\%$ relative luciferase activity b
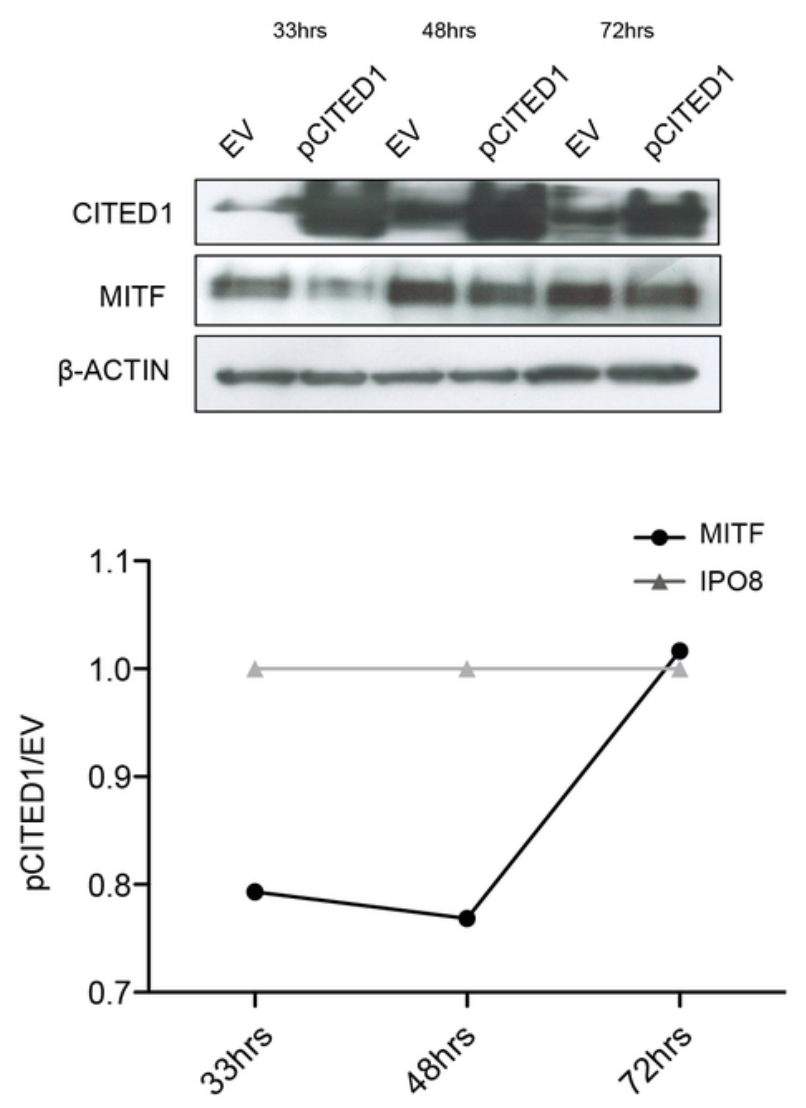


\section{7}

The CITED1-silenced gene signature predicts patient outcome

(a) In the leftmost panel a scatter plot of the 120 melanoma cell lines are shown distributed on the basis of their 'invasive' or 'proliferative' phenotype signature score and coloured according to the tumour molecular subtypes as defined by jönsson et al. to illustrate the overlap between the two classification systems (Jonsson et al. 2010) In the rightmost panel the data is presented as a heatmap where each gene of the proliferative or invasive signature genes is represented by a horizontal line and the 120 individual cells lines are grouped by molecular tumour subtype (coloured blocks) and shown vertically. (b) Recurrence free survival (RFS) of primary melanoma patients grouped by gene expression similarity to the CITED1 (siCITED1) silenced gene signature. 

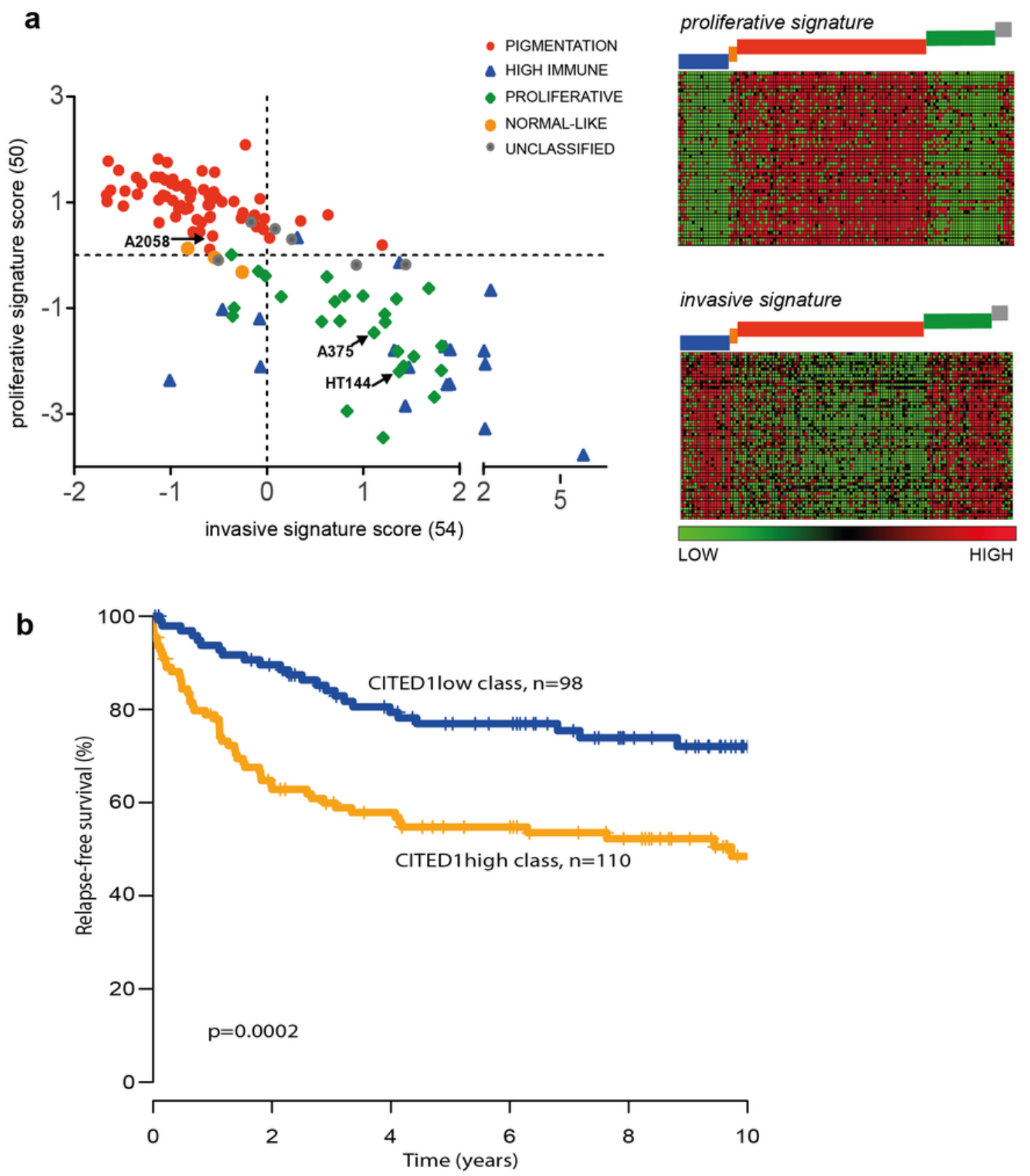